\title{
Is elective inguinal radiotherapy necessary for locally advanced rectal adenocarcinoma invading anal canal?
}

Seung-Gu Yeo ${ }^{1 \dagger}$, Hyeon Woo Lim² ${ }^{2 \dagger}$, Dae Yong Kim²,3* , Tae Hyun Kim², Sun Young Kim, Ji Yeon Baek ${ }^{3}$, Hee Jin Chang ${ }^{3}$, Ji Won Park ${ }^{3}$ and Jae Hwan $\mathrm{Oh}^{3}$

\begin{abstract}
Background: We investigated whether routine elective irradiation of a clinically negative inguinal node (IGN) is necessary for patients with locally advanced distal rectal cancer and anal canal invasion (ACl).

Methods: We reviewed retrospectively 1,246 patients with locally advanced rectal adenocarcinoma managed using preoperative or postoperative chemoradiotherapy and radical surgery between 2001 and 2011. The patients' IGN was clinically negative at presentation and IGN irradiation was not performed. ACI was defined as the lower edge of the tumor being within $3 \mathrm{~cm}$ of the anal verge. Patients were divided into two groups, those with $\mathrm{ACl}(\mathrm{n}=189$, 15.2\%) and without $\mathrm{ACl}(\mathrm{n}=1,057,84.8 \%)$.

Results: The follow-up period was a median of 66 months (range, 3-142 months). Among the 1,246 patients, 10 developed IGN recurrence; 7 with $\mathrm{ACl}$ and 3 without $\mathrm{ACl}$. The actuarial IGN recurrence rate at 5 years was $0.7 \%$; $3.5 \%$ and $0.2 \%$ in patients with and without $\mathrm{ACl}$, respectively $(p<0.001)$. Isolated IGN recurrence occurred in three patients, all of whom had ACl tumors. These three patients received curative intent local treatments, and one was alive with no evidence of disease 10 years after IGN recurrence. Salvage treatments in the other two patients controlled successfully the IGN recurrence for $>5$ years, but they developed second malignancy or pelvic and distant recurrences. Seven patients with non-isolated IGN recurrence died of disease at 5-22 months after IGN recurrence.
\end{abstract}

Conclusion: The low IGN recurrence rate even with $\mathrm{ACl}$ and the feasibility of salvage of isolated IGN recurrence indicated that routine elective IGN irradiation is not necessary for rectal cancer with ACl.

Keywords: Rectal cancer, Radiotherapy, Inguinal lymph node, Anal canal invasion

\section{Background}

The lymphatic drainage from the rectum occurs preferentially in a proximal direction. The lymphatic system supplies the mesenteric and para-aortic nodes through the perirectal and pelvic lymphatic vessels. However, when a distal rectal tumor invades the anal canal, the lymphatic system drains in another direction to the inguinal nodes (IGN), as observed in primary anal cancer, through the perirectal, perianal and pudendal lymphatics [1].

\footnotetext{
* Correspondence: radiopiakim@hanmail.net

${ }^{\dagger}$ Equal contributors

${ }^{2}$ Proton Therapy Center, Research Institute and Hospital, National Cancer

Center, Goyang, Korea

${ }^{3}$ Center for Colorectal Cancer, Research Institute and Hospital, National

Cancer Center, Goyang, Korea

Full list of author information is available at the end of the article
}

Radiation therapy (RT) is an important constituent of multi-modality management recommended for locally advanced (stage II or III) rectal cancer [2]. Preoperative or postoperative RT reduces local disease recurrence and the former improves resectability and sphincter preservation by downstaging or downsizing the tumor [3]. Conventional RT fields for rectal cancer encompass regional lymphatics which do not contain IGN [4], whereas standard RT fields for anal cancer involve IGN because the risk of local recurrence is high in this region without elective treatment [5]. Thus, for a subset of rectal cancer patients with anal canal invasion (ACI) and with potential lymphatic drainage to IGN, whether RT fields should be extended to involve IGN basins remains questionable [5].

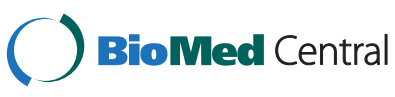

(C) 2014 Yeo et al.; licensee BioMed Central. This is an Open Access article distributed under the terms of the Creative Commons Attribution License (http://creativecommons.org/licenses/by/4.0), which permits unrestricted use, distribution, and reproduction in any medium, provided the original work is properly credited. The Creative Commons Public Domain Dedication waiver (http://creativecommons.org/publicdomain/zero/1.0/) applies to the data made available in this article unless otherwise stated. 
In our institution, the treatment policy for rectal cancer with clinically negative IGN at presentation has been no irradiation of IGN, regardless of tumor location. To determine the requirement for routine elective IGN irradiation for patients with distal rectal cancer and $\mathrm{ACI}$, we investigated the failure patterns and salvage feasibility regarding IGN recurrence and conducted a comparison between rectal tumors with and without $\mathrm{ACI}$.

\section{Methods \\ Patients}

A total of 1,246 patients with locally advanced rectal cancer treated with preoperative or postoperative chemoradiotherapy (CRT) and radical surgery between 2001 and 2011 at the National Cancer Center (Goyang, Korea) were reviewed retrospectively. The patients had histologically confirmed rectal adenocarcinoma and no evidence of distant metastasis, including IGN, at the time of initial workup and surgery. Concurrent CRT was administered preoperatively (cT3-4) or postoperatively (pT3-4 or $\mathrm{pN}+$ ) in 877 (70.4\%) and $369(29.6 \%)$ patients, respectively. Since the introduction of preoperative CRT at our institution in October 2001, routine treatment for clinically staged T3-4 rectal cancer located at the mid-to-low rectum $(\leq 9 \mathrm{~cm}$ from the anal verge) has gradually changed from postoperative to preoperative CRT. During and after the transition period, upfront surgery with postoperative CRT was performed routinely for upper rectal cancer, and for mid-to-low rectal cancer, it was determined by the preferences of patients or attending physicians.

Pretreatment workups for clinical staging included digital rectal examination, complete blood count, liver function tests, serum carcinoembryonic antigen tests, video colonoscopy, chest radiography and computed tomography (CT) scanning of the abdomen and pelvis with or without transrectal ultrasonography and pelvic magnetic resonance imaging (MRI). ${ }^{18} \mathrm{~F}$-deoxyfluoroglucose positron emission tomography-CT was performed as required. Clinically positive lymph node involvement was defined as a lymph node with the smallest diameter of $0.5 \mathrm{~cm}$, observed on CT or MRI. All stages were determined according to the American Joint Committee on Cancer Staging System, 7th edition [4]. Anal canal involvement (ACI) was defined when the lower edge of the tumor was within $3 \mathrm{~cm}$ from the anal verge on colonoscopy or digital rectal examination. Digital rectal examination for all patients in the present study was performed by one experienced radiation oncologist (Dr. DY Kim). Patients were grouped and compared according to the existence of ACI; 189 (15.2\%) with ACI and 1,057 (84.8\%) without ACI. All patients provided written informed consent before treatments and the study was performed in accordance with the guidelines of our Institutional Review Board of the National Cancer Center.

\section{Treatments}

Radiotherapy was delivered to the whole pelvis at a dose of 45 Gy in 25 fractions, followed by a 5.4-Gy boost in three fractions within 6 weeks. All patients underwent CT simulation for three-dimensional conformal planning, and a three-field treatment plan used a 6-MV photon posterior-anterior field and 15-MV photon-opposed lateral beams. The prescription dose was specified at the isocenter of the planning target volume. The initial radiation field encompassed the gross tumor and mesorectum (preoperative CRT) or tumor bed (postoperative CRT), presacral space, the entire sacral hollow and the regional lymphatics, including the perirectal, internal iliac, presacral and distal common iliac lymphatics. The superior border was placed at L5/S1 and the inferior border at $>3$ $\mathrm{cm}$ caudal to the gross tumor or tumor bed. The boost field included the gross tumor volume and mesorectum (preoperative CRT) or tumor bed (postoperative CRT), with $\geq 2 \mathrm{~cm}$ margin in all directions.

Chemotherapy administered concurrently with RT used one of the following regimens: fluoropyrimidine, irinotecan, or an oxaliplatin-based regimen. Patients underwent radical proctectomy, including high ligation of the inferior mesenteric vessels and total mesorectal excision. The interval between preoperative CRT and surgery was $4-8$ weeks, and 3-8 weeks between surgery and postoperative CRT. Postoperative chemotherapy was initiated 3-6 weeks after surgery or postoperative CRT, using fluoropyrimidine or an oxaliplatin-based regimen.

\section{Evaluation}

All patients underwent standardized follow-up, consisting of physical examination, complete blood count, liver function tests, serum carcinoembryonic antigen tests and chest radiography every 3 months for the first 2 years and every 6 months thereafter, as well as abdominopelvic CT every 6 months. Colonoscopic examinations were performed 1 year postoperatively and then at 2-year intervals. Recurrence was determined based on clinical, radiological or histological findings. Radiological evidence involved serial radiological examinations showing progressive mass growth, including abnormally high uptake on ${ }^{18} \mathrm{~F}$-deoxyfluoroglucose positron emission tomography.

\section{Analysis}

Intergroup comparisons regarding patient, tumor and treatment characteristics were conducted using the chisquare test, Fisher's exact test, linear-by-linear association, or $t$-test, depending on the nature of the data. Multivariate logistic regression was conducted to determine parameters that are related with IGN recurrence. Actuarial IGN recurrence rate was estimated using the Kaplan-Meier method and the significance of differences was assessed with the log-rank test. The level of statistical significance was set at 
$p<0.05$ and all reported $p$-values were two-tailed. Statistical analyses were performed using the SPSS software (version 14.0; SPSS Inc., Chicago, IL, USA).

\section{Results}

\section{Patients}

Patient, tumor and treatment characteristics according to existence of ACI in all 1,246 patients are listed in Table 1. Distance from anal verge to distal tumor end was a median of $2.0 \mathrm{~cm}$ (range, $0-3.0 \mathrm{~cm}$ ) in the ACI group and $7.0 \mathrm{~cm}$ (range, $3.5-13.0 \mathrm{~cm}$ ) in the non-ACI group. Female gender and a high histological grade were more frequent in rectal tumors with ACI. Preoperative CRT and irinotecan or an oxaliplatin-based regimen were prescribed more frequently for rectal tumors with $\mathrm{ACI}$. Abdominoperineal resection was performed in $66.7 \%$ of rectal tumors with ACI. The follow-up period of all 1,246 patients was a median of 66 months (range, 3-142 months). This was not different in 189 with ACI vs. 1,057 without ACI; $71.4 \pm 35.4$ vs. $68.8 \pm 33.1$ months, respectively $(p=0.333)$.

\section{Patterns of IGN recurrence}

Of 1,246 patients, 10 developed IGN recurrence; 7 with $\mathrm{ACI}$ and 3 without ACI. Characteristics of the $10 \mathrm{pa}$ tients are listed in Table 2. All 10 patients had disease in the regional pelvic lymph nodes initially and 2 had mucinous or signet ring cell carcinoma. Distance from the anal verge to the distal tumor end was a median of $1 \mathrm{~cm}$ (range, $0-2.5 \mathrm{~cm}$ ) in patients with ACI and ranged from $5-10 \mathrm{~cm}$ in patients without ACI. Patients' characteristics were compared according to IGN recurrence (Table 3). Significant difference existed in the rate of sphincter-sparing surgery, in addition to tumor distance

Table 1 Comparison of characteristics according to $\mathrm{ACl}$ in all patients

\begin{tabular}{|c|c|c|c|c|}
\hline & & With ACI $(n=192)$ & Without ACI $(n=1,054)$ & $p$-value ${ }^{\ddagger}$ \\
\hline Age (yr) & Mean \pm SD & $57.6 \pm 11.3$ & $58.2 \pm 10.8$ & 0.462 \\
\hline \multirow[t]{2}{*}{ Gender } & Male & $114(59.4)$ & $718(68.1)$ & 0.018 \\
\hline & Female & $78(40.6)$ & $336(31.9)$ & \\
\hline Distance from anal verge $(\mathrm{cm})$ & Mean \pm SD & $2.0 \pm 0.9$ & $6.9 \pm 2.1$ & $<0.001$ \\
\hline \multirow[t]{3}{*}{ Histological grade* } & Low & $171(90.0)$ & $989(96.2)$ & $<0.001$ \\
\hline & High & $19(10.0)$ & $39(3.8)$ & \\
\hline & $($ Not specified $=28)$ & & & \\
\hline \multirow[t]{2}{*}{ Clinical stage } & cStage II & $42(21.9)$ & $213(20.2)$ & 0.599 \\
\hline & cStage III & $150(78.1)$ & $841(79.8)$ & \\
\hline \multirow[t]{4}{*}{ Pathological stage } & ypStage 0 & $26(13.5)$ & $104(9.9)$ & 0.001 \\
\hline & ypStage I & $47(24.5)$ & $176(16.7)$ & \\
\hline & pStage II/ypStage II & $54(28.1)$ & $299(28.4)$ & \\
\hline & pStage III/ypStage III & $65(33.9)$ & $475(45.1)$ & \\
\hline \multirow[t]{2}{*}{ CRT timing } & Preoperative CRT & $168(87.5)$ & $709(67.3)$ & $<0.001$ \\
\hline & Postoperative CRT & $24(12.5)$ & $345(32.7)$ & \\
\hline \multirow[t]{3}{*}{ Concurrent chemotherapy } & Fluoropyrimidine alone & $166(86.5)$ & $960(91.8)$ & 0.018 \\
\hline & Irinotecan or oxaliplatin-based & $26(13.5)$ & $86(8.2)$ & \\
\hline & (None $=8)$ & & & \\
\hline \multirow[t]{2}{*}{ Surgery } & Sphincter-sparing surgery & $64(33.3)$ & $1,016(96.4)$ & $<0.001$ \\
\hline & Abdominoperineal resection & $128(66.7)$ & $38(3.6)$ & \\
\hline \multirow[t]{3}{*}{ CRM } & Negative $(>0.1 \mathrm{~cm})$ & $154(80.2)$ & $890(85.3)$ & 0.071 \\
\hline & Positive $(\leq 0.1 \mathrm{~cm})$ & $38(19.8)$ & $153(14.7)$ & \\
\hline & (Not specified $=11$ ) & & & \\
\hline \multirow[t]{2}{*}{ Postoperative chemotherapy } & Yes & $175(91.1)$ & $962(91.3)$ & 0.955 \\
\hline & $\mathrm{No}^{+}$ & $17(8.9)$ & $92(8.7)$ & \\
\hline
\end{tabular}

Abbreviations: $A C l$ anal canal invasion, $S D$ standard deviation, $C R T$ chemoradiotherapy, CRM circumferential resection margin.

${ }^{*}$ Evaluated by pretreatment diagnostic biopsy. Low indicates well or moderately differentiated; high indicates poorly differentiated, mucinous, or signet ring cell carcinoma.

${ }^{\dagger}$ Including patients who did not finish the planned chemotherapy.

${ }^{\ddagger}$ Chi-square test, linear-by-linear association, or $t$-test. 
Table 2 Characteristics of patients with IGN recurrence

\begin{tabular}{|c|c|c|c|c|c|c|}
\hline No & $\mathrm{ACl}$ & Gender/Age & cStage & pStage/ypStage & Hisological grade $^{\dagger}$ & Surgery \\
\hline 1 & Yes $(1.0)^{*}$ & $F / 38$ & CT3N1M0 & урT2N1bM0 & Low & LAR \\
\hline 2 & Yes (1.5) & $F / 57$ & cT4N1M0 & ypTONOMO & High & APR \\
\hline 3 & Yes (0.0) & $\mathrm{M} / 59$ & cT3N1M0 & ypT4bN1bM0 & Low & APR \\
\hline 4 & Yes (2.5) & M/55 & CT3N2MO & ypT3NOMO & Low & APR \\
\hline 5 & Yes (0.5) & $\mathrm{M} / 50$ & CT3N2MO & ypT2NOMO & Low & APR \\
\hline 6 & Yes (0.0) & $M / 58$ & CT3N1M0 & ypT4bN2aM0 & Low & APR \\
\hline 7 & Yes (2.0) & $F / 58$ & CT3N2MO & pT3N2aM0 & High & APR \\
\hline 8 & No (5.0) & $M / 57$ & cT3N2M0 & pT3N2aM0 & Low & LAR \\
\hline 9 & No $(9.0)$ & $M / 52$ & CT3N2MO & pT3N2bM0 & Low & LAR \\
\hline 10 & No (10.0) & $M / 54$ & CT3N2MO & pT3N2aM0 & Low & LAR \\
\hline
\end{tabular}

Abbreviations: IGN inguinal node, $A C l$ anal canal invasion, $L A R$ low anterior resection, $A P R$ abdominoperineal resection.

"Data in parenthesis are the distance $(\mathrm{cm})$ from the anal verge to the distal end of the tumor.

${ }^{\dagger}$ Evaluated by pretreatment diagnostic biopsy. Low indicates well or moderately differentiated; high indicates poorly differentiated, mucinous, or signet ring cell carcinoma.

Table 3 Comparison of characteristics according to IGN recurrence in all patients

\begin{tabular}{|c|c|c|c|c|}
\hline & & With IGN recurrence $(n=10)$ & Without IGN recurrence $(n=1,236)$ & $p$-value ${ }^{\ddagger}$ \\
\hline Age (yr) & Mean \pm SD & $53.8 \pm 6.3$ & $58.1 \pm 10.9$ & 0.057 \\
\hline \multirow[t]{2}{*}{ Gender } & Male & $7(0.8)$ & $825(99.2)$ & 1.000 \\
\hline & Female & $3(0.7)$ & $411(99.3)$ & \\
\hline Distance from anal verge $(\mathrm{cm})$ & Mean \pm SD & $3.4 \pm 3.8$ & $6.2 \pm 2.6$ & 0.046 \\
\hline \multirow[t]{3}{*}{ Histological grade* } & Low & $8(0.7)$ & $1152(99.3)$ & 0.078 \\
\hline & High & $2(3.4)$ & $56(96.6)$ & \\
\hline & (Not specified $=28$ ) & & & \\
\hline \multirow[t]{2}{*}{ Clinical stage } & cStage II & 0 & $255(100)$ & 0.229 \\
\hline & cStage III & $10(1.0)$ & $981(99.0)$ & \\
\hline \multirow[t]{4}{*}{ Pathological stage } & ypStage 0 & $1(0.8)$ & $129(99.2)$ & 0.267 \\
\hline & ypStage I & $1(0.4)$ & $222(99.6)$ & \\
\hline & pStage II/ypStage II & $1(0.3)$ & $352(99.7)$ & \\
\hline & pStage III/ypStage III & $7(1.3)$ & $533(98.7)$ & \\
\hline \multirow[t]{2}{*}{ CRT timing } & Preoperative CRT & $6(0.7)$ & $871(99.3)$ & 0.494 \\
\hline & Postoperative CRT & $4(1.1)$ & $365(98.9)$ & \\
\hline \multirow[t]{3}{*}{ Concurrent chemotherapy } & Fluoropyrimidine alone & $10(0.9)$ & $1116(99.1)$ & 0.613 \\
\hline & Irinotecan or oxaliplatin-based & 0 & $112(100)$ & \\
\hline & $($ Not specified $=8)$ & & & \\
\hline \multirow[t]{2}{*}{ Surgery } & Sphincter-sparing surgery & $4(0.4)$ & $1076(99.6)$ & 0.001 \\
\hline & Abdominoperineal resection & $6(3.6)$ & $160(96.4)$ & \\
\hline \multirow[t]{3}{*}{ CRM } & Negative $(>0.1 \mathrm{~cm})$ & $9(0.9)$ & $1035(99.1)$ & 1.000 \\
\hline & Positive $(\leq 0.1 \mathrm{~cm})$ & $1(0.5)$ & $190(99.5)$ & \\
\hline & $($ Not specified $=11)$ & & & \\
\hline \multirow[t]{2}{*}{ Postoperative chemotherapy } & Yes & $10(0.9)$ & $1127(99.1)$ & 1.000 \\
\hline & $\mathrm{No}^{+}$ & 0 & $109(100)$ & \\
\hline
\end{tabular}

Abbreviations: IGN inguinal node, SD standard deviation, CRT chemoradiotherapy, CRM circumferential resection margin.

*Evaluated by pretreatment diagnostic biopsy. Low indicates well or moderately differentiated; high indicates poorly differentiated, mucinous, or signet ring cell carcinoma.

${ }^{\dagger}$ Including patients who did not finish the planned chemotherapy.

${ }^{\ddagger}$ Fisher's exact test, linear-by-linear association, or $t$-test. 
from the anal verge; however, only the tumor distance maintained its statistical significance in the multivariate analysis $(\leq 3 \mathrm{~cm} v s .>3 \mathrm{~cm}$; odds ratio $7.287,95 \%$ confidence interval $1.102-48.171, p=0.039$ ).

Actuarial IGN recurrence at 5 years was $0.7 \%$. When estimated separately in patients with and without ACI, the rates were $3.5 \%$ and $0.2 \%$, respectively $(p<0.001)$. The disease-free interval until IGN recurrence was a median of 29 months (range, 8-105 months) from initial management; $27.9 \pm 16.5$ vs. $50.3 \pm 49.1$ months with and without ACI, respectively ( $p=0.513)$.

Isolated IGN recurrence occurred in three patients, all of whom had tumors with ACI. The other seven patients showed additional synchronous recurrences; both pelvic recurrence and distant metastasis in four, distant metastasis without pelvic recurrence in two, and one showed pelvic recurrence first at 93 months; this patient subsequently (1 year later) developed IGN recurrence and peritoneal seeding.

\section{Salvage outcomes}

Salvage outcomes of the 10 patients with IGN recurrence are described in Table 4. Among the seven patients with $\mathrm{ACI}$, isolated IGN recurrence occurred in three and IGN recurrence combined with pelvic recurrence and/or distant metastasis in four. All three patients with isolated IGN recurrence received curative intent local treatments. Concurrent CRT was performed in two patients (patients \#1 and 2) and surgical excision followed by concurrent CRT in one (patient \#3). RT target included only the involved groin region and prescribed total RT doses were 63, 72, and 54 Gy, respectively, in the three patients. Status at the last follow-up showed no evidence of disease for 10 years after salvage treatment in one patient (patient \#1). Salvage treatments in the other two patients controlled successfully the IGN recurrence for $>5$ years, but second malignancy or disease recurrence occurred; one (patient \#2) developed endometrial cancer 31 months after salvage resulting in death, and the other (patient \#3) is alive but developed lung metastasis, pelvic and retroperitoneal lymph node recurrences 38 months after salvage. Four patients (patients \#4-7) with ACI and non-isolated IGN recurrence received palliative chemotherapy but died of the disease at 5-22 months after IGN recurrence.

Non-isolated IGN recurrence occurred in all three patients without ACI. They received palliative CRT, chemotherapy, pelvic exenteration or supportive care, but died of rectal cancer at 8,11 , and 20 months after IGN recurrence.

\section{Discussion}

In the 2009 consensus report of the Radiation Therapy Oncology Group on the definition of clinical target volume for anorectal cancer, the panel group was divided as to whether elective irradiation of the IGN region in rectal adenocarcinomas with ACI is necessary [5]. So far, few studies have focused on the optimal RT fields for rectal cancer with ACI. Taylor et al. [6] assessed IGN recurrence rates in rectal cancer with ACI after preoperative or postoperative pelvic RT, of which the treatment field did not include the groin region. The 5-year IGN recurrence rate was $4 \%$ (6 of 184 patients) in rectal cancer with ACI. In other patients with rectal tumors and without $\mathrm{ACI}$, the 5 -year IGN recurrence rate was $<1 \%$ ( 3 of 350 patients). Based on their observation of low recurrence rates in IGN and the historical reports of groin RT-related morbidities, the authors insisted against routine elective groin irradiation for rectal cancer with ACI. The present study analyzed a larger number of patients and reported similar IGN recurrence rates. The 5-year IGN recurrence rate was $3.5 \%$ in 189 patients with rectal

Table 4 Salvage outcomes of patients with IGN recurrence

\begin{tabular}{|c|c|c|c|c|c|c|}
\hline No & $\begin{array}{l}\text { Isolated IGN } \\
\text { recurrence }\end{array}$ & $\begin{array}{l}\text { Synchronously } \\
\text { recurrent sites }\end{array}$ & $\begin{array}{l}\text { Laterality of } \\
\text { IGN recurrence }\end{array}$ & $\begin{array}{l}\text { Time to IGN } \\
\text { recurrence (months) }\end{array}$ & $\begin{array}{l}\text { Survival after IGN } \\
\text { recurrence (months) }\end{array}$ & Last status \\
\hline 1 & Yes & & Bilateral & 8 & 120 & NED \\
\hline 2 & Yes & & Unilateral & 61 & 63 & Dead $^{*}$ \\
\hline 3 & Yes & & Unilateral & 20 & 61 & AWD \\
\hline 4 & No & Brain & Bilateral & 29 & 5 & DWD \\
\hline 5 & No & LPN, PAN & Bilateral & 30 & 21 & DWD \\
\hline 6 & No & LPN, PAN & Unilateral & 28 & 22 & DWD \\
\hline 7 & No & PAN & Unilateral & 19 & 11 & DWD \\
\hline 8 & No & Tumor bed, lung & Unilateral & 36 & 20 & DWD \\
\hline 9 & No & LPN, PAN & Bilateral & 10 & 11 & DWD \\
\hline 10 & No & LPN, seeding & Unilateral & $105^{\dagger}$ & 8 & DWD \\
\hline
\end{tabular}

Abbreviations: IGN inguinal node, LPN lateral pelvic node, PAN para-aortic node, NED no evidence of disease, $A W D$ alive with disease, DWD dead with disease. "IGN recurrence was successfully salvaged with concurrent CRT, but endometrial cancer developed 31 months after IGN recurrence that progressed to lung metastasis and peritoneal seeding causing death.

${ }^{\dagger}$ Recurrence developed initially in the tumor bed at 93 months and non-isolated IGN recurrence occurred 1 year later. 
tumors with $\mathrm{ACI}$ and $0.2 \%$ in 1,057 patients without ACI. These outcomes support the insistence that routine irradiation of clinically negative IGN in rectal cancers with ACI is difficult to be justified.

In contrast, Lee et al. [7] reported that elective irradiation of IGN is highly effective in controlling its subclinical disease with minimal morbidity. They performed elective IGN irradiation in patients with pelvic tumors suspected to be at significant $(>10 \%)$ risk of harboring occult subclinical disease in IGN. Primary tumor sites were heterogeneous, and included the cervix, vagina, rectum (with ACI), anus, vulva, urethra, and penis. Of 164 patients treated, 105 (rectum $=22$ ) were eligible for analysis of IGN control. IGN recurrence was not detected in rectal cancer patients but developed in three patients with vulvar cancer and one with cervical cancer; the IGN recurrence rate was $4 \%$ at 2 years. However, the authors excluded seven patients with IGN recurrence (primary not specified) from IGN control analysis because the pelvic recurrence preceded their IGN recurrences. They thought that in this situation, IGN recurrence occurred by reseeding from the pelvic recurrence, which could cause bias in the analysis. In the present study, pelvic recurrence was present with or before IGN recurrence in half $(5 / 10)$ of the patients with IGN recurrence. In the lower rectum, the difference in local anatomy (limited visualization and access) and surgical technique applied (abdominoperineal resection) lead to more frequent local pelvic recurrences compared with in the mid or upper rectum $[8,9]$. When pelvic recurrence develops, interruption of ascending lymphatic drain due to a previous lymphadenectomy causes retrograde lymphatic flow into the IGN [10]. If these cases were excluded from our analysis using the same approach, estimated IGN recurrence risk in patients with ACI would be further decreased.

Pelvic recurrence and/or distant metastasis was detected synchronously with IGN recurrence in rectal tumors without ACI, whereas isolated IGN recurrence developed only in rectal tumors with $\mathrm{ACI}$, both in the present study and that by Taylor et al. [6]. Salvage therapy for isolated IGN recurrence appeared to yield durable control in the IGN region. Taylor et al. [6] treated three rectal cancer patients with isolated IGN recurrence using groin RT and subsequent chemotherapy. All achieved local control in the groin region, although one patient subsequently developed pelvic and distant metastases. Mesko et al. [11] reported that the median survival of rectal cancer patients $(n=4)$ with isolated IGN recurrence was significantly better than that of those $(n=9)$ with non-isolated IGN recurrence $(20$ vs. 12 months from IGN recurrence; $p=0.045$ ). In a case series, Bardia et al. [12] suggested that solitary IGN metastasis, either at presentation or metachronous, may represent a distinct subset of distal rectal cancer with a more favorable prognosis compared with other metastatic rectal cancers. Graham et al. [13] reported that isolated IGN recurrence developed only in patients whose primary rectal tumor was located within $3 \mathrm{~cm}$ of the anal verge and who had an earlier tumor stage at presentation compared with those who developed non-isolated IGN recurrence. All eight patients with isolated IGN recurrence underwent groin dissection; six survived more than 2 years after. In the present study, salvage therapy using concurrent CRT and/or surgical excision yielded long-term control of recurrent disease in IGN (10 years in one and $>5$ years in two patients; Table 3 ). The isolated IGN recurrence may be considered an oligometastatic state, which is increasingly regarded as an adequate indication for curative-intent local RT [14]. Our group reported favorable outcomes following definitive RT for solitary para-aortic nodal metastasis from colorectal cancer [15]. If isolated IGN recurrence represents the true recurrence risk due to the existence of $\mathrm{ACI}$, and salvage of this type of recurrence is feasible, the wait-and-see policy in IGN basins for rectal cancer with ACI could be supported.

Enlargement of the RT field to encompass the groin region is associated with a variety of acute and late morbidities, such as desquamation and fibrosis of the inguinal skin, wound and bowel complications, and edema of the extremities and femoral neck fractures [6]. To avoid these morbidities, omission of prophylactic inguinal irradiation is suggested for early-stage (cT1) anal cancer, which shows a $<5 \%$ IGN failure rate when IGN irradiation is eliminated [16-19]. However, innovative RT technologies, including intensity-modulated RT and proton therapy, will reduce the exposure of normal organs to radiation and accordingly the radiation-related morbidities in the treatment of anorectal cancer [20]. Furthermore, identification of the disease characteristics linked to an increased risk of developing IGN recurrence in addition to ACI will assist in decisions regarding elective IGN irradiation in the minority of patients who will benefit from this treatment despite the potential for complications. Research in rectal cancer has included the sentinel node procedure [21], serial acquisition of ${ }^{18} \mathrm{~F}$-deoxyfluoroglucose positron emission tomography-CT [22], and the study of histological tumor features at the distal front invading the dentate line [23].

\section{Conclusion}

Although in the present study IGN recurrence from rectal cancer developed more frequently in the presence of $\mathrm{ACI}$, the 5-year rate was 3.5\% despite the fact that the IGN region was not irradiated. Isolated IGN recurrence occurred only from rectal tumors with ACI and increased the IGN recurrence rate of these rectal tumors; however, salvage of isolated IGN recurrence appeared feasible. Our results indicated that routine elective IGN irradiation is unnecessary for distal rectal cancer with ACI. 


\section{Competing interests}

The authors declare that they have no competing interests.

\section{Authors' contributions}

DYK contributed to conception and design of the study, and revised the manuscript. SGY and HWL contributed to analysis and interpretation of data and drafted the manuscript. THK, SYK, JYB, HJC, JWP, and JHO participated in acquisition, analysis of data and literature research. All authors read and approved the final manuscript.

\section{Acknowledgements}

This work was supported by 1) a National Cancer Center Grant (NCC-1310070), and 2) the Soonchunhyang University Research Fund.

\section{Author details}

${ }^{1}$ Department of Radiation Oncology, Soonchunhyang University College of Medicine, Choenan, Korea. ${ }^{2}$ Proton Therapy Center, Research Institute and Hospital, National Cancer Center, Goyang, Korea. ${ }^{3}$ Center for Colorectal Cancer, Research Institute and Hospital, National Cancer Center, Goyang, Korea.

Received: 24 June 2014 Accepted: 10 December 2014

Published online: 23 December 2014

\section{References}

1. Luna-Perez P, Corral P, Labastida S, Rodriguez-Coria D, Delgado S: Inguinal lymph node metastases from rectal adenocarcinoma. J Surg Oncol 1999, 70:177-180.

2. Lee JW, Lee JH, Kim JG, Oh ST, Chung HJ, Lee MA, Chun HG, Jeong SM, Yoon SC, Jang HS: Comparison between preoperative and postoperative concurrent chemoradiotherapy for rectal cancer: an institutional analysis. Radiat Oncol J 2013, 31:155-161.

3. Sauer R, Becker H, Hohenberger W, Rodel C, Wittekind C, Fietkau R, Martus P, Tschmelitsch J, Hager E, Hess CF, Karstens JH, Liersch T, Schmidberger H, Raab R: Preoperative versus postoperative chemoradiotherapy for rectal cancer. N Engl J Med 2004, 351:1731-1740.

4. Edge S, Byrd DR, Compton CC, Fritz AG, Greene FL, Trotti A (Eds): American Joint Committee on Cancer Staging Manual. 7th edition. New York: Springer; 2010.

5. Myerson RJ, Garofalo MC, El Naqa I, Abrams RA, Apte A, Bosch WR, Das P, Gunderson LL, Hong TS, Kim JJ, Willett CG, Kachnic LA: Elective clinical target volumes for conformal therapy in anorectal cancer: a radiation therapy oncology group consensus panel contouring atlas. Int J Radiat Oncol Biol Phys 2009, 74:824-830.

6. Taylor N, Crane C, Skibber J, Feig B, Ellis L, Vauthey JN, Hamilton S, Cleary K, Dubrow R, Brown T, Wolff R, Hoff P, Sanfilippo N, Janjan N: Elective groin irradiation is not indicated for patients with adenocarcinoma of the rectum extending to the anal canal. Int J Radiat Oncol Biol Phys 2001, 51:741-747.

7. Lee WR, McCollough WM, Mendenhall WM, Marcus RB Jr, Parsons JT, Million RR: Elective inguinal lymph node irradiation for pelvic carcinomas. The University of Florida experience. Cancer 1993, 72:2058-2065.

8. Hwang MR, Park JW, Kim DY, Chang HJ, Hong YS, Kim SY, Choi HS, Jeong SY, Oh JH: Prognostic impact of peritonealisation in rectal cancer treated with preoperative chemoradiotherapy: extraperitoneal versus intraperitoneal rectal cancer. Radiother Oncol 2010, 94:353-358.

9. Nagtegaal ID, van de Velde CJ, Marijnen CA, van Krieken JH, Quirke P: Low rectal cancer: a call for a change of approach in abdominoperineal resection. J Clin Oncol 2005, 23:9257-9264.

10. Tocchi A, Lepre L, Costa G, Liotta G, Mazzoni G, Agostini N, Miccini M: Rectal cancer and inguinal metastases: prognostic role and therapeutic indications. Dis Colon Rectum 1999, 42:1464-1466.

11. Mesko TW, Rodriguez-Bigas MA, Petrelli NJ: Inguinal lymph node metastases from adenocarcinoma of the rectum. Am J Surg 1994, 168:285-287.

12. Bardia A, Greeno E, Miller R, Alberts S, Dozois E, Haddock M, Limburg P: Is a solitary inguinal lymph node metastasis from adenocarcinoma of the rectum really a metastasis? Colorectal Dis 2010, 12:312-315.

13. Graham RA, Hohn DC: Management of inguinal lymph node metastases from adenocarcinoma of the rectum. Dis Colon Rectum 1990, 33:212-216.

14. Badakhshi H, Grun A, Stromberger C, Budach V, Boehmer D: Oligometastases: the new paradigm and options for radiotherapy: a critical review. Strahlenther Onkol 2013, 189:357-362.
15. Yeo SG, Kim DY, Kim TH, Jung KH, Hong YS, Kim SY, Park JW, Choi HS, Oh $\mathrm{JH}$ : Curative chemoradiotherapy for isolated retroperitoneal lymph node recurrence of colorectal cancer. Radiother Oncol 2010, 97:307-311.

16. Ortholan C, Resbeut M, Hannoun-Levi JM, Teissier E, Gerard JP, Ronchin P, Zaccariotto A, Minsat M, Benezery K, Francois E, Salem N, Ellis S, Azria D, Champetier C, Gross E, Cowen D: Anal canal cancer: management of inguinal nodes and benefit of prophylactic inguinal irradiation (CORS-03 Study). Int J Radiat Oncol Biol Phys 2012, 82:1988-1995.

17. Ng M, Leong T, Chander S, Chu J, Kneebone A, Carroll S, Wiltshire K, Ngan S, Kachnic L: Australasian Gastrointestinal Trials Group (AGITG) contouring atlas and planning guidelines for intensity-modulated radiotherapy in anal cancer. Int J Radiat Oncol Biol Phys 2012, 83:1455-1462.

18. Tomaszewski JM, Link E, Leong T, Heriot A, Vazquez M, Chander S, Chu J, Foo M, Lee MT, Lynch CA, Mackay J, Michael M, Tran P, Ngan SY: Twenty-fiveyear experience with radical chemoradiation for anal cancer. Int J Radiat Oncol Biol Phys 2012, 83:552-558.

19. Blinde SE, Schasfoort R, Mens JW, Verhoef C, Olofsen M, Nuyttens JJ: Inguinal lymph node recurrence in the untreated groin of patients with anal carcinoma. Dis Colon Rectum 2014, 57:578-584.

20. Meyer J, Czito B, Yin FF, Willett C: Advanced radiation therapy technologies in the treatment of rectal and anal cancer: intensitymodulated photon therapy and proton therapy. Clin Colorectal Cancer 2007, 6:348-356.

21. Damin DC, Tolfo GC, Rosito MA, Spiro BL, Kliemann LM: Sentinel lymph node in patients with rectal cancer invading the anal canal. Tech Coloproctol 2010, 14:133-139.

22. Perez RO, Habr-Gama A, Sao Juliao GP, Proscurshim I, Ono CR, Lynn P, Bailao Aguilar P, Nahas SC, Gama-Rodrigues J, Buchpiguel CA: Clinical relevance of positron emission tomography/computed tomography-positive inguinal nodes in rectal cancer after neoadjuvant chemoradiation. Colorectal Dis 2013, 15:674-682.

23. Hamano T, Homma Y, Otsuki Y, Shimizu S, Kobayashi H, Kobayashi Y: Inguinal lymph node metastases are recognized with high frequency in rectal adenocarcinoma invading the dentate line. The histological features at the invasive front may predict inguinal lymph node metastasis. Colorectal Dis 2010, 12:e200-e205.

\section{Submit your next manuscript to BioMed Central and take full advantage of:}

- Convenient online submission

- Thorough peer review

- No space constraints or color figure charges

- Immediate publication on acceptance

- Inclusion in PubMed, CAS, Scopus and Google Scholar

- Research which is freely available for redistribution 